\title{
Can boreal afforestation help offset incompressible GHG emissions from Canadian industries?
}

\author{
J.-F. Boucher ${ }^{a, *}$, P. Tremblay ${ }^{a}$, S. Gaboury ${ }^{b}$, C. Villeneuve ${ }^{a}$ \\ a Université du Québec à Chicoutimi, Chair on eco-advising, Dép. Sciences fondamentales, 555 boul. de l’Université, Chicoutimi, QC, \\ Canada G7H 2B1 \\ $\mathrm{b}$ Rio Tinto Alcan, Centre de Recherche et de développement Arvida (CRDA), 1955 Boulevard Mellon, Jonquière, QC, Canada G7S 4K8
}

\begin{abstract}
A B S T R A C T
To mitigate greenhouse gas and comply with cap-and-trade systems, the carbon capture and storage (CCS) is presently unviable for industrials dealing with low concentration of $\mathrm{CO}_{2}$ emissions. Alternatively, a new offset opportunity is being analysed in Canada: the afforestation of open woodlands (OWs) in the boreal territory. The results obtained from model simulations (with CBM-CFS3) showed that afforestation of boreal OWs can be a low C-intensive mitigation activity, in particular when understory planting is the chosen silvicultural approach, so that only 8-12 years are needed to reach a net positive $C$ balance with the afforestation of OWs. A large-scale afforestation of boreal OWs - scheduled at 20 kha per year during 20 years for a maximum of $400 \mathrm{kha}$ - could provide capped industrials with a significant offset potential, for instance up to nearly $8 \%$ offset of all Québec industrial process emissions (2009 data) after 45 years. In spite of a certain number of issues that can contribute to the uncertainty of the real environmental and economical benefits from the afforestation of OWs as a mitigation activity - most of which issues are discussed in this paper - this study presented a first glimpse at the extent to which the afforestation of boreal OWs in Québec can provide large emitters with eventually substantial and efficient GHG offset potential, especially those emitters tied up with incompressible GHG emissions.
\end{abstract}

(c) 2012 The Institution of Chemical Engineers. Published by Elsevier B.V. All rights reserved.

Keywords: Afforestation; Boreal forest; Climate change; GHG emissions; Mitigation; Smelters

\section{Introduction}

\subsection{World demographic and industrial context}

Last United Nations (UN) report on world demography (UNFPA, 2011) indicates that world population will continue to grow during the 21st century, stabilizing in 2100 around 10 billion humans, a 1.5 fold increase compared to 2008 records. Most of this growth will occur in the less advanced countries, especially in Africa, where the actual poverty is rampant. Insuring the quality of life of nations in the Organization for economic co-operation and development (OECD) for the world population in 2050, would require a 15 fold growth in world economy, and a 40 fold growth would be required to fulfil this objective by 2100 (Jackson, 2009). OECD (2012) however predicts a 4 fold growth for the world economy by 2050, resulting in an increase in energy use of $80 \%, 85 \%$ being provided by fossil fuels in a business as usual (BAU) scenario. This will result in a $70 \%$ increase of $\mathrm{CO}_{2}$ emissions and an atmospheric concentration of $685 \mathrm{ppm}$ of $\mathrm{CO}_{2}$ by 2050 . Even with strong efforts to increase renewable energy sources and energy efficiency, the Intergovernmental Panel on Climate Change (IPCC, 2011) expects that it would result in only a stabilization of the fossil fuels use by 2035 compared to 2008 . The real scenario will probably be somewhere in between the OECD BAU and the IPCC best case, the three highest emitting economies in the world (China, USA and India) having no binding commitment or targets for absolute emission reductions. The Copenhagen Accord commitments being unable to lower significantly the GHG emission patterns towards 2050 (OECD, 2012), the pressure on

* Corresponding author. Tel.: +1 418545 5011x5385; fax: +1 4186151203.

E-mail addresses: Jean-Francois_Boucher@uqac.ca (J.-F. Boucher), Pascal_Tremblay@uqac.ca (P. Tremblay), simon.gaboury@riotinto.com (S. Gaboury), Claude_Villeneuve@uqac.ca (C. Villeneuve).

Accepted 6 October 2012

0957-5820/\$ - see front matter @ 2012 The Institution of Chemical Engineers. Published by Elsevier B.V. All rights reserved. http://dx.doi.org/10.1016/j.psep.2012.10.011 
industrial emissions reduction will likely increase, as highlighted by the forecast of the International Energy Agencies (IEA, 2009).

The IEA studies forecasted a significant growth of $55 \%$ in GHG emissions from industries under the BAU scenario, from 2006 to 2050 (IEA, 2009). If all known reduction potential were to be applied, including best available technology implementation, energy efficiency, fossil fuel substitution, and even carbon capture and storage (CCS) where possible, the remaining emissions could be decreased by close to $20 \%$ compared to 2006 level. As a matter of fact, if CCS can be applied at relatively low costs in industrials where $\mathrm{CO}_{2}$ emissions are concentrated, such as for energy, ammonia and ethanol productions, its application - given the current technological knowledge would be highly uncertain or expensive for industrials at the other end of the spectrum with low $\mathrm{CO}_{2}$ process gas concentrations, such as for aluminium smelting (IEA, 2009). Industrials like aluminium smelting have in fact few remaining opportunities to lower direct GHG emissions, after significant past reduction in process emissions and today's best available technology implementation (IAI, 2010). Consequently, large emitters with low concentration of GHG emissions must look for other ways to mitigate their emissions.

\subsection{Negative emission technology and the boreal afforestation}

The eventual stabilization of the atmospheric $\mathrm{CO}_{2}$ concentrations and the reduction of the risk to reach dangerous climate change - corresponding to levels often referred to $2^{\circ} \mathrm{C}$ above pre-industrial temperatures (The Copenhagen Diagnosis, 2009) - will require both the accomplishment of the zero emission goal during the 21st century, and the drawdown of long-lived anthropogenic atmospheric GHGs (Fisher et al., 2007; Weaver et al., 2007; Matthews and Caldeira, 2008; Solomon et al., 2009; Zickfeld et al., 2009). To achieve this task, mitigation activities ought to be supplemental to reduction measures, and must insure that extracted GHGs from the atmosphere are locked away permanently. Such plea for "negative emission technologies" (NET) aims at stocking indefinitely GHGs in biosphere reservoirs, for example C in plants, soil and deep underground. The combination of bioenergy production with CCS (known as BECCS), or the burying of biochar (charring of biomass) in the ground, are often cited NET technologies (Fisher et al., 2007; Hare, 2009). Afforestation activities can also qualify as NET, providing that at least part of the $\mathrm{C}$ sequestered in the different forest reservoirs is permanently stocked (e.g. Marland et al., 2001; Obersteiner et al., 2010), in both on-site and off-site C reservoirs - i.e. in harvested wood products (Perez-Garcia et al., 2005; Garcia-Quijano et al., 2008; Hennigar et al., 2008).

According to the last assessment report of the IPCC (Nabuurs et al., 2007), the potential volume of afforestation measures accounts globally for approximately $29 \%$ of the total potential volume $\left(<100 \mathrm{US} \$ / \mathrm{tCO}_{2}\right)$ of activities in the land-use, land-use change and forestry (LULUCF) sector, after deforestation reduction (29\%) and forest management (42\%) measures (top-down models). While the respective contribution of each of the three types of measures in the LULUCF sector vary greatly geographically (Nabuurs et al., 2007), the potential contribution to global mitigation efforts of afforestation in the boreal zone was, and still remains, largely unknown. However, a recent study revealed the projected net (life-cycle approach) sequestration potential of $280 \mathrm{tCO}_{2} \mathrm{e}, 70$ years after the

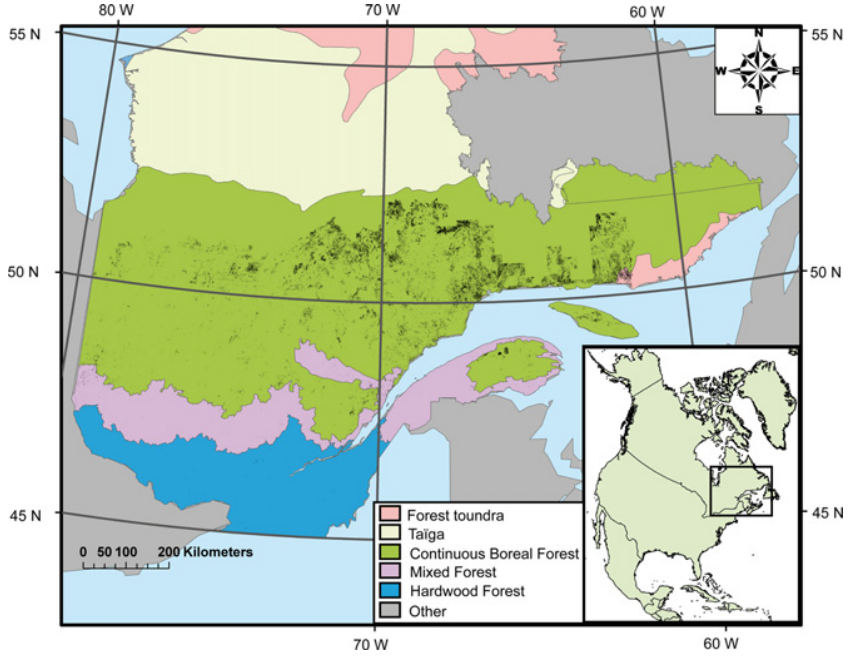

Fig. 1 - Present distribution of OWs in the Province of Québec, based on the 3rd decennial forest inventory of the MRNF. The OWs are represented by the small black dots. The northern distribution of the OWs corresponds to the northern limit of the allowable territory for forest management in the Province of Québec.

afforestation of 1 theoretical hectare of boreal open woodland (OW) in the province of Québec, a so far unrevealed niche for afforestation activities (Gaboury et al., 2009). This mitigation potential could be an interesting substitute to CCS for industrials with low $\mathrm{CO}_{2}$ concentrations. In the Québec Province alone, direct industrial process emissions were reported at $10.12 \mathrm{MtCO}_{2} \mathrm{e}$ in 2009, 59\% coming from aluminium smelting, therefore not appropriate for CCS in the medium term (MDDEP, 2011).

The OWs in Canada's Eastern continuous boreal forest (between the 48th and the 52th parallels, Fig. 1) are the result of regeneration failure that sometimes occur after consecutive natural disturbances, leading to the irreversible conversion of closed-crown stands to OWs (Payette, 1992; Payette et al., 2000; Gagnon and Morin, 2001; Jasinski and Payette, 2005; Brown and Johnstone, 2011). The OWs are by definition unforested lands - according to Canada's definition of forest, i.e. tree crown cover $>25 \%$ (Environment Canada, 2006) - which makes them eligible to afforestation activity per se (IPCC, 2003). The last complete Québec's forest inventory (MRNF, 3rd decennial forest inventory) reveals that approximately $7 \%(1.6 \mathrm{M} \mathrm{ha})$ of the continuous boreal forest in the province of Québec is covered by OWs (Fig. 1), with a significant proportion close to the extending road network (Plante, 2003). Detailed and reliable data on the boreal OW availability throughout the rest of the Canadian territory is lacking, but there are indications suggesting a substantial potential availability of OWs within the present managed forest limits - probably up to several million hectares (Rowe, 1972; CCFM, 2006).

One of the key elements regarding the boreal OWs, is that there is presently no evidence of natural re-densification of OWs, i.e. a shifting from OWs to closed-crown stands, so that afforestation is the only known mechanism that can lead to the closed-crown forest structure (Payette, 1992; Jasinski and Payette, 2005; Hébert et al., 2006; Gaboury et al., 2009). This is crucial with regards to the additionality criteria of mitigation activities, i.e. activities which GHG absorptions (or emission reductions) go beyond that of the BAU scenario (ISO, 2006; UNFCCC, 2008). Some other elements with the afforestation of boreal OWs are also important assets, compared to other 
mitigation technologies: large available territories, low Cintensive technology, low technological risk, cheap technology, and environmental friendly approach (Fisher et al., 2007; Nabuurs et al., 2007; Gaboury et al., 2009). Afforestation of OWs have been tested only recently, and indicated a shortterm support capacity to tree growth of afforested OWs (Hébert et al., 2006) and also revealed some silvicultural solutions that increase the efficiency of afforested OWs as a mitigation measure (Fradette, 2012; Madec et al., in press), compared to the theoretical base case of Gaboury et al. (2009). Modelling can be of great help to calculate the C-implications of a GHG mitigation project by comparing simulations of BAU and a change in management (Kurz et al., 2009). The present study aims at using these recent results to guide the model simulation of new afforestation scenarios, in order to contribute to the progression of boreal OW afforestation from a potential mitigation activity towards a competitive NET.

\section{Materials and methods}

Model simulations have been done with the Carbon Budget Model of the Canadian Forest Sector 3 (v1.2) (hereafter shorten to CBM-CFS3), using the stand level project creator (Kurz et al., 2009). CBM-CFS3 is an aspatial, stand- and landscape-level modelling framework to simulate the dynamics of all forest carbon stocks required under the Kyoto Protocol, and is compliant with the carbon estimation methods outlined in the IPCC Good Practice Guidance for Land Use, Land-Use Change and Forestry report (IPCC, 2003). Simulations have been run with CBM-CFS3 within the Québec administrative boundary in the Eastern boreal shield ecozone, using Québec's growth and yield table (MRN, 2000). The baseline scenario for the simulation was a typical OW of the Québec's boreal forest, i.e. a non-forest unproductive stand with tree crown cover less than $25 \%$, and merchantable tree volume less than $30 \mathrm{~m}^{3}$ at 120 years of age (MRNFP, 2003). The growth and yield table used to simulate this baseline scenario is that of Pothier and Savard (1998) natural Black spruce low density stand, with a site index (SI) of $9 \mathrm{~m}$ at 50 years, which corresponds to the upper limit (for the sake of conservatism) of both the unproductive OW definition (MRNFP, 2003) and Canada's definition of a non-forest (Environment Canada, 2006). The time duration of each simulation varied according to the afforestation scenario to which an OW was associated, but as the starting age of an afforested OW was 70 years (as in Gaboury et al., 2009) the duration varied from a minimum of 140 years (for a minimal 70 year-old plantation) to 190 years (for a maximal 120 year-old plantation). It should be noted that since the total duration of each simulation creates the initial site conditions of each simulation with CBM-CFS3, 200-year long growth and yield tables were used as imported data in all simulations, for homogeneity.

For the afforestation scenarios, understory planting (2000 stems ha ${ }^{-1}$ ) with three tree species was first simulated at the stand (1 ha) level: Black spruce (hereafter BS), Jack pine (Pinus banksiana Lamb.) (JP) and Tamarack (Larix laricina (Du Roi) K. Koch) (TAM). The understory planting was started when the OW subjected to planting was 70 year-old, and was simulated for at least a 70-year long period and up to a maximum of 120 years, depending on the afforestation scenario scheduled (see below). For BS and TAM, growth and yield tables used to feed the CBM-CFS3 were based on MRN (2000) tables using the lowest productivity plantation table available (BS SI: $6 \mathrm{~m}$ at 25 years, TAM SI: $8 \mathrm{~m}$ at 25 years). For JP the MRN (2000) tables were used to calculate a SI $4.5 \mathrm{~m}$ at 15 years table, based on recent (unpublished) results with 10-year old afforested OWs (Fradette, 2012), where JP growth measured corresponded to that of SI $4.5 \mathrm{~m}$, a slightly higher SI than the lowest table SI (which vary from SI 3 to $8 \mathrm{~m}$ at 15 years). This afforestation scenario with JP thereby corresponded to the best-case scenario in the present simulations.

Once the initial simulations were done with the three planted tree species during a 70-year long period at the stand level, the carbon stocks of the different afforestation scenarios were compared against the unmanaged natural ow (baseline scenario) carbon stocks. The difference between the afforestation and the baseline scenarios (from year 70 to 140) - using the CBM-CFS3 outputs imported in Excel (Microsoft corp., Redmond, USA) files - then corresponded to the net C stocked of each afforestation scenarios. The impact of soil scarification has been integrated by removing $4 \mathrm{tCha}^{-1}\left(14.7 \mathrm{t} \mathrm{CO}_{2} \mathrm{ha}^{-1}\right)$ throughout the duration (for the sake of conservatism) of each afforestation scenario, based on field results with 10-year old planted (and scarified) OWs (Fradette, 2012). A fourth simulation, with planted BS, was also made to reproduce the Gaboury et al. (2009) base case scenario, by removing (harvesting) the $C$ stocks associated to all the mature trees in the OWs with the BS afforestation scenario.

Two sets of large scale afforestation of boreal OWs were also simulated. They were scheduled over $400 \mathrm{kha}$ (or $800 \mathrm{M}$ planted trees at 2000 trees ha $^{-1}$ ) - i.e. $25 \%$ (a guesstimated technical potential) of the theoretical available OWs within the managed boreal territory in the Province of Québec (1.6 Mha, according to Québec's third decennial forest inventory) - and during 20-50 years, depending on the pace of plantation establishment, i.e. whether at a $2 \%$ ( 8 kha per year during 50 years) or a $5 \%$ (20 kha per year during 20 years) pace. Considering that between 1989 and 2009 the plantation rate in the Province of Québec averaged $165 \mathrm{M}$ seedlings year $^{-1}$ (MRNF, 2010), or a correspondent $82.5 \mathrm{kha} \mathrm{year}^{-1}$, these annual plantation rates used were $10-25 \%$ of the historical annual rate in Québec. As a result of the two plantation rates simulated, the total duration of the scheduled large-scale afforestation scenarios was 120 years, with $2-5 \%$ (8-20 kha) of all scheduled plantations having a maximum of 120 years of age, and $2-5 \%$ having a minimum of 70 years of age. The two sets of large-scale afforestation scenarios were based on different mixtures of planted species: whether the three tree species were equally planted annually $(33 \% \mathrm{BS}+33 \% \mathrm{JP}+33 \% \mathrm{TAM})$, or they were tested in individual simulations (100\% BS vs $100 \%$ JP vs $100 \%$ TAM). The growth and yield possible variability (from site to site) was included in the simulations of the former species mixture, by producing $\pm 20 \%$ variations on the merchant volume $\left(\mathrm{m}^{3}\right)$ at each time step.

\section{Results}

Stand level simulations of understory planting with Black spruce (BS), Jack pine (JP), and Tamarack (Tam) resulted in net positive $C$ balance in 12,8 , and 10 years, respectively, while 29 years were necessary with the combination of tree harvesting + plantation with BS (as in Gaboury et al., 2009) (Fig. 2) The highest $C$ stocked simulated after 70 years was with JP, followed by BS, Tam, and the reproduction of Gaboury et al. (2009) simulation (Fig. 2).

Large scale level ( $400 \mathrm{kha}$ ) simulations resulted in net positive $C$ balance within 20 years after the first plantation, with a 


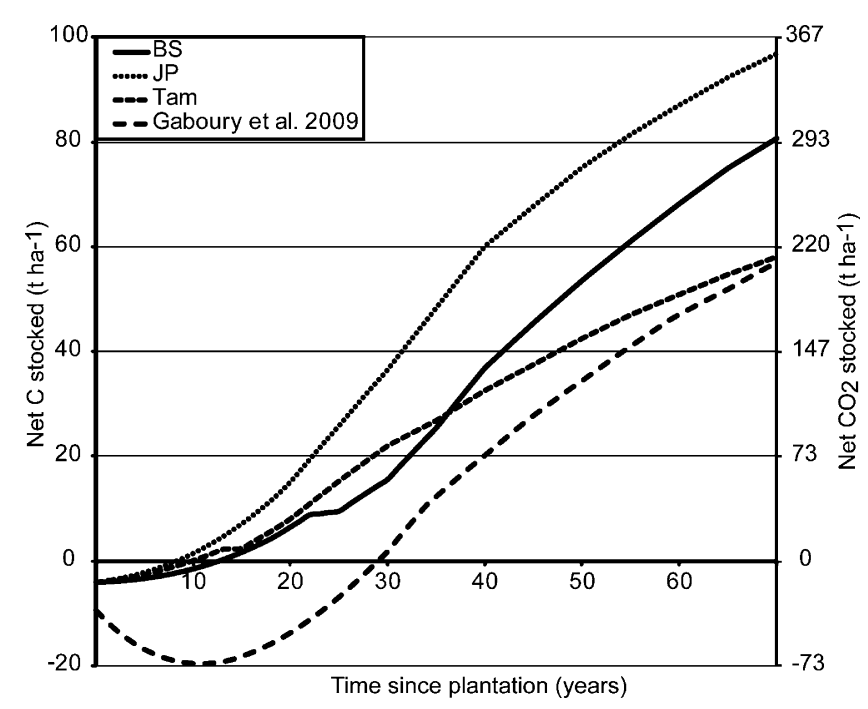

Fig. 2 - Cumulative net C stocked of stand level $(1 \mathrm{ha})$ boreal OWs afforestation scenarios (2000 trees ha ${ }^{-1}$ ) with Black spruce (BS), Jack pine (JP), Tamarack (Tam) over 70 years of plantation growth. The fourth curve is the reproduction of the Gaboury et al. (2009) simulation (harvesting + plantation with BS). The afforestation scenarios are net from the ow baseline scenario (70 year-old BS open woodland with less than $25 \%$ tree crown cover and maximum $30 \mathrm{~m}^{3}$ merchantable tree volume at 120 years).

faster rate at the $5 \%$ afforestation pace $(20$ kha per year during 20 years) compared to the $2 \%$ pace ( $8 \mathrm{kha}$ per year during 50 years), and when using JP in monocultures (Fig. 3). The worst case scenario was with planted Tam at the $2 \%$ afforestation pace, while the best case scenario was with both planted JP at the $5 \%$ afforestation pace (Fig. $3 \mathrm{~b}$ ) and the species mixture $+20 \%$ of volume growth and at the $5 \%$ afforestation pace (Fig. 3a).

\section{Discussion}

Results obtained from the present simulation efforts confirm that afforestation of boreal OWs is a low C-intensive mitigation activity, both at the stand and the large-scale project

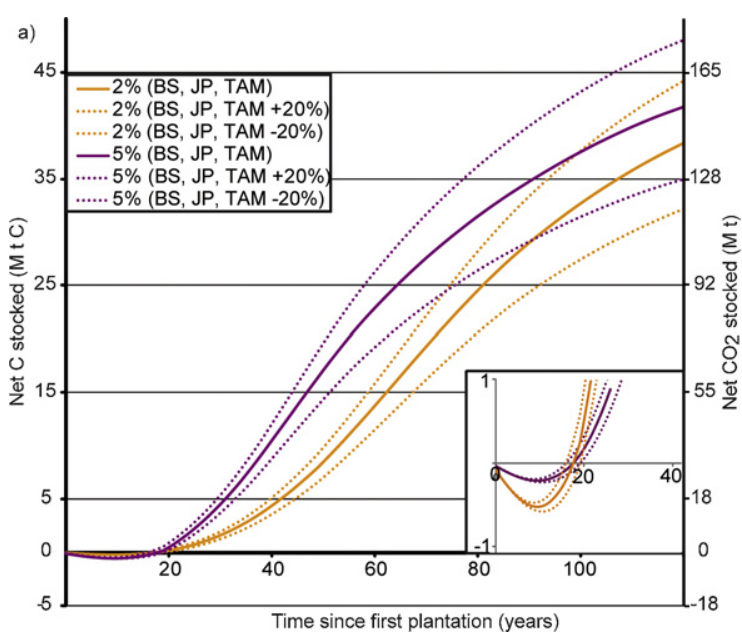

levels. At the stand level, all three simulations with different tree species showed shorter duration of net cumulated C emissions, with 8-12 years of emissions according to the species choice, compared with 26 years in the base-case scenario in Gaboury et al. (2009). This gain in efficiency can be essentially attributed to the change in the silvicultural approach in the present study, where tree harvesting was not included in the simulations, unlike the base-case scenario in Gaboury et al. (2009). The reproduction of the base-case scenario in the present simulations attests that most of that difference in the duration in net $\mathrm{C}$ emissions is not resulting from the change in the model used (CO2FIX v.3.1 in Gaboury et al., 2009 vs CBMCFS3 in the present study) - though the substantial difference found between both studies in the cumulated $\mathrm{C}$ stocked after 70 years (77 t C ha ${ }^{-1}$ in Gaboury et al., 2009 vs $58 \mathrm{t} \mathrm{C} \mathrm{ha}^{-1}$ in the present study). The 2-3 times longer duration of net cumulated emissions due to tree harvesting is essentially caused by both (i) the $C$ loss from the extraction of the merchantable part of trees (considered emitted to the atmosphere) and (ii) the $\mathrm{C}$ emitted by the decomposition of the organic matter left on the ground after tree cutting (Giasson et al., 2006; Humphreys et al., 2006; Bergeron et al., 2008). Harvestingrelated operations were shown to cause marginal emissions (246 kg CO $\mathrm{e} \mathrm{ha}^{-1}$ ) in a LCA approach (Gaboury et al., 2009), and emissions from other known silvicultural operations (especially nitrogen fertilization and soil drainage) can be excluded from a boreal OW afforestation project on this typically dry site conditions and where $\mathrm{N}$ fertilization is traditionally not prescribed (in Québec's context) (Gaboury et al., 2009; Chair on eco-advising, 2012). The understory tree planting (including natural seeding) in boreal OWs has been shown to be both feasible and viable in terms of site support capacity, and planted tree survival and growth, at least during the first 10 years after site preparation (soil scarification) and afforestation (Hébert et al., 2006; Delisle, 2012; Madec et al., in press). Moreover, recent (unpublished) field results validated that net positive $C$ balance, compared to the baseline scenario (intact OWs), can be reached within 10 years of growth in conditions of understory planting, especially with the planted-shade intolerant Jack pine (Fradette, 2012).

At the large-scale level, the simulated afforestation of boreal OWs scheduled over $400 \mathrm{kha}-25 \%$ (a guesstimated

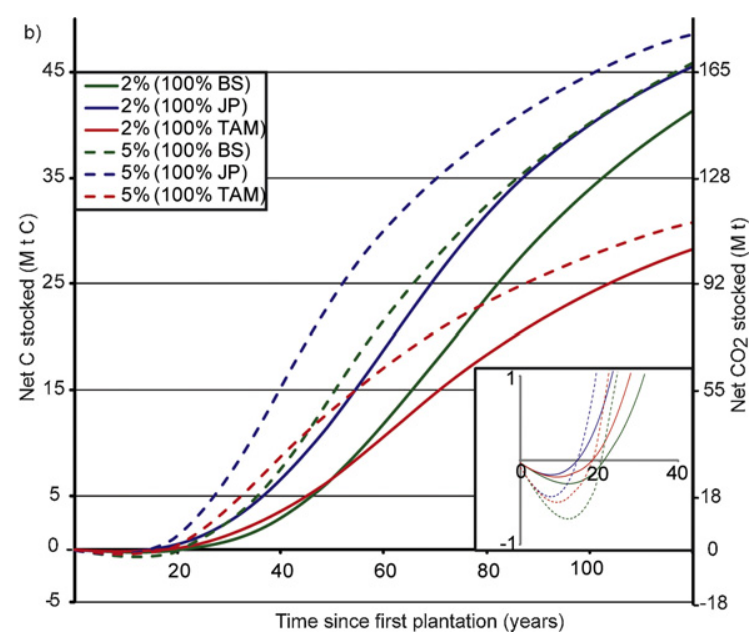

Fig. 3 - Cumulative net C stocked of large scale $(400,000 \mathrm{ha}$ ) level boreal OWs afforestation scenarios, with (a) mixtures (33-33-33\%) or (b) monocultures of Black spruce (BS), Jack pine (JP), and Tamarack (Tam) over 120 years of scheduled plantations (70 year-long scenarios), whether at a $2 \%$ ( 8 kha per year during 50 years) or a $5 \%$ (20 kha per year during 20 years) pace. The small boxes in the lower right corners are excerpts zooming on the first 40 years of each simulation for more clarity on the initial emission period; note that scaling is different than from the original graph. 


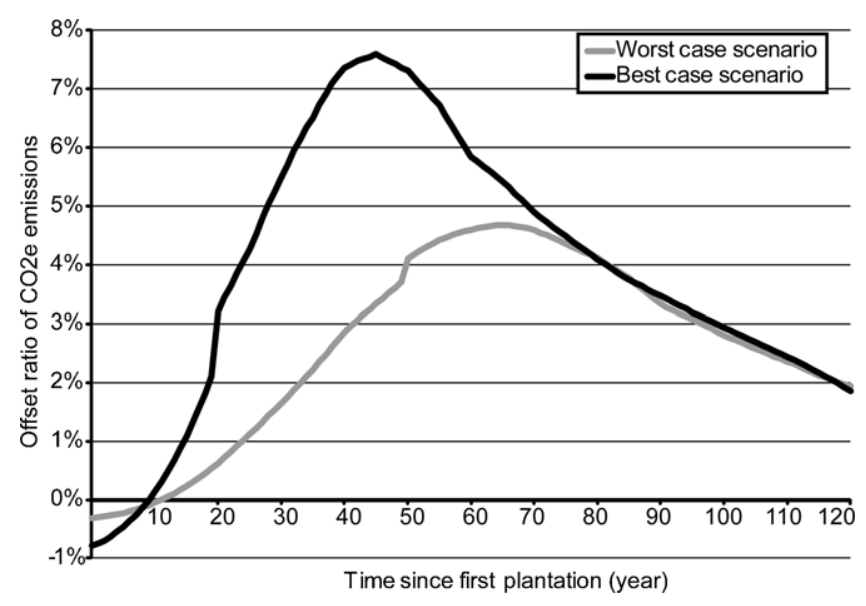

Fig. 4 - Evolution of the offset ratio of $\mathrm{CO}_{2} \mathrm{e}$ emitted from industrial process emissions in the Province of Québec (10.12 $\mathrm{Mt} \mathrm{CO}_{2}$ e year ${ }^{-1}, 2009$ data; MDDEP, 2011). The worst case ( $2 \%$ BS-JP-Tam $-20 \%)$ and best case ( $5 \%$ BS-JP-Tam $+20 \%$ ) scenarios of $\mathrm{CO}_{2}$ uptake rate are from Fig. $3 \mathrm{a}$.

technical potential) of the theoretical available OWs within the managed boreal territory in the Province of Québec - during 20-50 years, revealed the importance of both the choice of planted species and the pace of the afforestation schedule. The choice of the planted species simulated pointed to Jack pine as the primary choice for faster and greater levels of $\mathrm{C}$ stocked, as expected for this relatively fast growing species compared to Black spruce and Tamarack. The pace of plantation establishment - whether at a $2 \%$ (8 kha per year during 50 years) or a $5 \%$ ( 20 kha per year during 20 years) pace - showed a noticeable impact particularly on the rate of the accumulated C stocks, with approximately twice the C stocked with the $5 \%$ compared to $2 \%$ rate, at only 40 years after the first plantation. This finding is of primary importance in the actual context of urgent need for actions against global warming that produce rapid results, especially while the short- or mid-term achievement of the zero emission goal seems unlikely (Fisher et al., 2007; Nabuurs et al., 2007; Weaver et al., 2007; Matthews and Caldeira, 2008; Solomon et al., 2009).

The implementation of a successful and large-scale afforestation effort within the boreal forest territory in the Province of Québec, cannot be realistically envisaged without the incentive influence of the $\mathrm{C}$ markets. Actually, the different installations subjected to the cap-and-trade system of the newly established Western Climate Initiative (WCI) can use offset credits up to $8 \%$ of the capped emissions, so that the demand for credible offset credits will eventually increase. In order to evaluate to what offset level would correspond the simulated $C$ sequestration of the present study, the bestcase and the worst-case scenarios from Fig. 3a were used to project the \% offset of the 2009 industrial process emissions in the Province of Québec (10.12 $\mathrm{Mt} \mathrm{CO}_{2}$ e year ${ }^{-1}$; MDDEP, 2011) that the afforestation of boreal OWs can offer (Fig. 4). This calculation exercise first indicates that offsets would be created 10 years after the beginning of the scheduled large-scale afforestation for both scenarios, and that the best case scenario would reach nearly 8\% offset of all Québec industrial process emissions after 45 years, while the worst case scenario would peak at close to $5 \%$ after 65 years (with a sustained 2009 level of emissions).

The simulations and potential offset opportunity presented in this study are, as any mitigation measure, subjected to a certain number of issues that can contribute to the uncertainty of the real environmental and economical benefits that can be obtained from the afforestation of OWs as a mitigation activity. First, the long-term growth and support capacity of afforested OWs needs to be validated, since the oldest known plantations in boreal OWs are less than 15year old to date (Hébert et al., 2006). Furthermore, boreal OWs have been rarely studied and are hypothetically considered bearing limitations to growth, like those reported for Kalmia angustifolia-Rhododendron groenlandicum heaths of the NorthEast American boreal forest (Mallik, 1993; Thiffault et al., 2005; Thiffault and Jobidon, 2006; Hébert et al., 2010a,b). Certainly, more research is needed in this regard. Also, the management of the risks associated to offset plantations, particularly the risk of reversibility (Marland et al., 2001; Dutschke et al., 2005; Kirschbaum, 2006), is an important responsibility for project promoters. Though the reversibility of forest sinks - especially because of natural disturbances like wildfires and insect outbreaks (Amiro et al., 2001; Bond-Lamberty et al., 2004; Kurz et al., 2007, 2008) - adds on the uncertainty of long-term permanence of C sequestration (e.g. Mansuy et al., 2012), the potential of forest sequestration as an efficient mitigation method remains important, even if temporary at the stand level (Dornburg and Marland, 2008; Fearnside, 2008). At the larger scale level, increased sink capacity from newly established forested areas can provide long term (centuries) stocked $C$ in several on-site and off-site C reservoirs, especially in humus, soils, and harvested wood products (Marland et al., 2001; Perez-Garcia et al., 2005; Nabuurs et al., 2007; GarciaQuijano et al., 2008; Hennigar et al., 2008; Chen et al., 2010; FAO, 2010; Obersteiner et al., 2010). The management of C stock buffers - supplementary to project C stocks - in forest offset projects are now mandatory with the most renown offset project standards, e.g. the Verified Carbon Standard (VCS, 2011) and Climate Action Reserve (CAR, 2010). One of the advantages with the afforestation of boreal OWs, compared to southern territories, is the extensive territory available throughout Canada, so that buffer plantations can be managed without constraining the actual offset plantations, or conflicting with other human activities because of the uninhabited - and unsuitable for cultivation - nature of the boreal forest. These assets can probably be also attributed to the Russian boreal territory, where an immense afforestation potential has been revealed (Shvidenko et al., 1997). Incidentally, the CBM-CFS3 model has recently been applied at the national scale in Russia, and due to its comprehensive nature the model can be used in small-scale or regional applications in other countries (Kurz et al., 2009).

Another important issue with the afforestation in the boreal zone is the surface albedo impact of land-use change activities, which can induce a positive radiative forcing (warming) that can counteract the negative forcing (cooling) induced by increased C sequestration (e.g. Gibbard et al., 2005; Bala et al., 2007; Betts et al., 2007; Bernier et al., 2011). While there is an ongoing discussion on to what extent these two forcing agents are equivalent (e.g. Davin et al., 2007; Montenegro et al., 2009; Lee, 2010; Leu, 2010; Yakir and Rotenberg, 2010), or how other surface phenomena can also play a role as forcing agents (e.g. Kurtén et al., 2003; Juang et al., 2007), it seems likely that the albedo impact can also be managed to optimize the mitigation efficiency of boreal afforestation activities. In particular, the albedo impact can be mitigated by carefully planned selection of OWs for afforestation projects, or by the choice of deciduous tree species for plantation (e.g. Shuman et al., 2011), 
knowing that most of the albedo impact is occurring during the winter season (Bernier et al., 2011). The simulations with Tamarack in the present study were intended to address this option. Clearly, more research is needed on this issue.

The accessibility for the implementation, quantification, monitoring and verification of afforested OWs is also an important factor that can greatly influence the feasibility and the cost of this mitigation measure. Road construction may represent a large part of the initial costs necessary for the implementation of offset plantations, if there is no nearby pre-existing road network, and may also generate significant GHG emissions that would decrease the mitigation benefits of afforested OWs (Gaboury et al., 2009). The projections in the present study pertain only to afforestation efforts with a nearby pre-existing road network (with minimal road construction, as in Gaboury et al., 2009), but it is clear that road construction would need to be factored in for large-scale afforestation efforts outside the pre-existing road network (Chair on eco-advising, 2012). Even though afforestation is among the cheapest mitigation measures (Nabuurs et al., 2007), the up-front investments necessary for afforestation activities can also be an important decision-orienting factor. Soft site-silvicultural approaches - no tree harvesting, no fertilization, no drainage, minimal road construction, and possibly the natural seeding approach (Madec et al., in press) included in the present simulations are certainly contributing in keeping low the in-front investments, but new economical studies would be helpful at determining how different afforestation scenarios can influence the net present value (NPV) of the afforestation of OWs.

\section{Conclusion}

In conclusion, the results obtained showed that afforestation of boreal OWs can be a low C-intensive mitigation activity, in particular when understory planting is the chosen silvicultural approach. It was estimated that this approach cuts down by two to three fold the period of net $\mathrm{C}$ emissions associated to the traditional harvesting + plantation approach, so that only 8-12 years are needed to reach a net positive $C$ balance with the afforestation of OWs. The choice of the relatively fast growing tree species Jack pine, over Black spruce and Tamarack also tested in the present study, gave the best results regarding both the $\mathrm{C}$ sequestration rate and the long-term total stocking of C. Opting for a faster (but plausible) pace of afforestation in a large-scale ( $400 \mathrm{kh}$ a total) effort within Québec's boreal forest - from 8 kha per year during 50 years to 20 kha per year during 20 years - resulted in a significantly higher rate of accumulated C stocks, with approximately twice the $C$ stocked at only 40 years after the first plantation. Within a regulated offset system, this large-scale afforestation of boreal OWs could provide capped industrials with a significant offset potential, for instance up to nearly 8\% offset of all Québec industrial process emissions (2009 data) after 45 years. In spite of a certain number of issues that can contribute to the uncertainty of the real environmental and economical benefits that can be obtained from the afforestation of OWs as a mitigation activity - especially, the long term support capacity, the risk of reversibility, the albedo-related radiative forcing, the accessibility, and the up-front investments - this study presented a first glimpse at the extent to which the afforestation of boreal OWs in Québec (and probably elsewhere in Canada and in Russia) can provide large emitters with eventually substantial and efficient GHG offset potential, especially those emitters tied up with incompressible GHG emissions.

\section{Acknowledgements}

We thank sincerely Stephen J. Kull (Forest Carbon Accounting team, CFS), for helpful advices provided during the model simulations. This research was funded by the Natural Sciences and Engineering Research Council of Canada (NSERC) - Collaborative Research and Development Grant to J.-F. Boucher, and UQAC's Carbone boréal programme.

\section{References}

Amiro, B.D., Stocks, B.J., Alexander, M.E., Flannigan, M.D., Wotton, B.M., 2001. Fire, climate change, carbon and fuel management in the Canadian boreal forest. Int. J. Wildland Fire 10, 405-413.

Bala, G., Caldeira, K., Wickett, M., Phillips, T.J., Lobell, D.B., Delire, C., Mirin, A., 2007. Combined climate and carbon-cycle effects of large-scale deforestation. Proc. Natl. Acad. Sci. U.S.A. 104 (16), 6550-6555.

Bergeron, O., Margolis, H.A., Coursolle, C., Giasson, M.-A., 2008. How does forest harvest influence carbon dioxide fluxes of black spruce ecosystems in eastern North America? Agric. Forest Meterol. 148 (4), 537-548.

Bernier, P.Y., Desjardins, R.L., Karimi-Zindashty, Y., Worth, D., Beaudoin, A., Luo, Y., Wang, S., 2011. Boreal lichen woodlands: a possible negative feedback to climate change in eastern North America. Agric. Forest Meterol. 151, 521-528.

Betts, R.A., Falloon, P.D., Goldewijk, K.K., Ramankutty, N., 2007. Biogeophysical effects of land use on climate: model simulations of radiative forcing and large-scale temperature change. Agric. Forest Meterol. 142, 216-233.

Bond-Lamberty, B., Wang, C., Gower, S.T., 2004. Net primary production and net ecosystem production of a boreal black spruce wildfire chronosequence. Global Change Biol. 10, 473-487.

Brown, C.S., Johnstone, J.F., 2011. Once burned, twice shy: repeat fires reduce seed availability and alter substrate constraints on Piceamariana regeneration. Forest Ecol. Manage. 266, 34-41.

Canadian Council of Forest Ministers (CCFM), 2006. Canada's National Forest Inventory. Natural Resources Canada, Canadian Forest Service, Victoria, BC, Canada. https://nfi.nfis.org/reporting.php?lang=en (accessed 31.05.12).

Chair on eco-advising, 2012. Quantification Protocol for Afforestation Projects in Open Woodlands of the Closed-Crown Boreal Forest (v4.2). Université du Québec à Chicoutimi, Québec, Canada http://carboneboreal.uqac.ca/validation-verification.php (accessed 31.05.12).

Chen, J., Colombo, S.J., Ter-Mikaelian, M.T., Heath, L.S., 2010. Carbon budget of Ontario's managed forests and harvested wood products, 2001-2100. Forest Ecol. Manage. 259, 1385-1398.

Climate Action Reserve (CAR), August, 2010. Forest Project Protocol, Version 3.2. Climate Action Reserve, Los Angeles, CA. Davin, E.L., de Noblet-Ducoudré, N., Friedlingstein, P., 2007. Impact of land cover change on surface climate: relevance of the radiative forcing concept. Geophys. Res. Lett. 34, L13702.

Delisle, I., 2012. Croissance et rendement de la régénération naturelle d'épinettes noires (Piceamariana (Mill.) B.S.P.) après traitements sylvicoles dans les terrains dénudés boréaux. Maîtrise en Ressources renouvelables (Master degree thesis). Université du Québec à Chicoutimi (UQAC), Département des Sciences fondamentales, Chicoutimi, QC (Canada).

Dornburg, V., Marland, G., 2008. Temporary storage of carbon in the biosphere does have value for climate change mitigation: a response to the paper by MikoKirschbaum. Mitig. Adapt. Strat. Global Change 13, 211-217.

Dutschke, M., Schlamadinger, B., Wong, J.L.P., Rumberg, M., 2005. Value and risks of expiring carbon credits from afforestation 
and reforestation projects under the CDM. Climate Policy 5, 109-125.

Environment Canada, 2006. Canada's Greenhouse Gas Inventory: 1990-2004 - Greenhouse Gas Sources and Sinks in Canada. Environment Canada, Greenhouse Gas Division, Ottawa, Canada.

Fearnside, P., 2008. On the value of temporary carbon: a comment on Kirschbaum. Mitig. Adapt. Strat. Global Change 13, 207-210.

Fisher, B.S., Nakicenovic, N., Alfsen, K., CorfeeMorlot, J., de la Chesnaye, F., Hourcade, J.-Ch., Jiang, K., Kainuma, M., La Rovere, E., Matysek, A., Rana, A., Riahi, K., Richels, R., Rose, S., van Vuuren, D., Warren, R., 2007. Issues related to mitigation in the long term context. In: Metz, B., Davidson, O.R., Bosch, P.R., Dave, R., Meyer, L.A. (Eds.), Climate Change 2007: Mitigation. Contribution of Working Group III to the Fourth Assessment Report of the Inter-governmental Panel on Climate Change. Cambridge University Press, Cambridge, UK.

Food and Agriculture Organization of the United Nations (FAO), 2010. Global Forest Resources Assessment 2010. FAO Forestry Paper 163. Rome, Italy.

Fradette, O., 2012. Croissance des stocks de carbone dix ans après boisement de terrains dénudés boréaux (Carbon stock growth ten year after afforestation in boreal open woodlands). Maîtrise en Ressources renouvelables (Master degree thesis). Université du Québec à Chicoutimi (UQAC), Département des Sciences fondamentales, Chicoutimi, QC, Canada.

Gaboury, S., Boucher, J.-F., Villeneuve, C., Lord, D., Gagnon, R., 2009. Estimating the net carbon balance of boreal open woodland afforestation: a case-study in Québec's closed-crown boreal forest. Forest Ecol. Manage. 257, 483-494.

Gagnon, R., Morin, H., 2001. Les forêts d'épinette noire du Québec: dynamique, perturbations et biodiversité. Nat. Can. 125, 26-35.

Garcia-Quijano, J., Deckmyn, G., Ceulemans, R., van Orshoven, J., Muys, B., 2008. Scaling from stand to landscape scale of climate change mitigation by afforestation and forest management: a modeling approach. Climatic Change 86, $397-424$.

Giasson, M.-A., Coursolle, C., Margolis, H.A., 2006. Ecosystemlevel $\mathrm{CO}_{2}$ fluxes from a boreal cutover in eastern Canada before and after scarification. Agric. Forest Meteorol. 140, 23-40.

Gibbard, S., Caldeira, K., Bala, G., Phillips, T.J., Wickett, M., 2005. Climate effects of global land cover change. Geophys. Res. Lett. 32, Art. No. L23705.

Hare, W.L., 2009. A safe landing for the climate. In: State of the World 2009: Into a Warming World. The Worldwatch Institute, Washington, DC, USA.

Hébert, F., Boucher, J.-F., Bernier, P.Y., Lord, D., 2006. Growth response and water relations of 3-year-old planted black spruce and jack pine seedlings in site prepared LW stands. Forest Ecol. Manage. 223, 226-236.

Hébert, F., Thiffault, N., Ruel, J.-C., Munson, A.D., 2010a. Ericaceous shrubs affect black spruce physiology independently from inherent site fertility. Forest Ecol. Manage. 260, 219-228.

Hébert, F., Thiffault, N., Ruel, J.-C., Munson, A.D., 2010 b. Comparative physiological responses of Rhododendron groenlandicum and regenerating Piceamariana following partial canopy removal in northeastern Quebec, Canada. Can. J. Forest Res. 40, 1791-1802.

Hennigar, C.R., MacLean, D.A., Amos-Binks, L.J., 2008. A novel approach to optimize management strategies for carbon stored in both forests and wood products. Forest Ecol. Manage. 256, 786-797.

Humphreys, E.R., Black, T.A., Morgenstern, K., Cai, T., Drewitt, G.B., Nesic, Z., Trofymow, J.A., 2006. Carbon dioxide fluxes in coastal Douglas-fir stands at different stages of development after clearcut harvesting. Agric. Forest Meteorol. 140, 6-22.

Intergovernmental Panel on Climate Change (IPCC), 2003. In: Penmam, J., Gytarsky, M., Hiraishi, T., Krug, T., Kruger, D., Pipatti, R., Buendia, L., Miwa, K., Ngara, T., Tanabe, K., Wagner, F. (Eds.), Good Practice Guidance for Land Use, Land-Use Change and Forestry. Institute for Global Environmental Strategies (IGES), Cambridge University Press, Cambridge, UK.
IPCC, 2011. In: Edenhofer, O., Pichs-Madruga, R., Sokona, Y., Seyboth, K., Matschoss, P., Kadner, S., Zwickel, T., Eickemeier, P., Hansen, G., Schlömer, S., von Stechow, C. (Eds.), IPCC Special Report on Renewable Energy Sources and Climate Change Mitigation. Prepared by Working Group III of the Intergovernmental Panel on Climate Change. Cambridge University Press, Cambridge, United Kingdom/New York, NY, USA.

IAI, 2010. Result of the 2009 Anode Effect Survey: Report on the Aluminium Industry's Global Perfluorocarbon Gases Emissions Reduction Programme. International Aluminium Institute, London, UK.

International Energy Agency (IEA), 2009. Energy Technology Transition for Industry: Strategies for the Next Industrial Revolution. International Energy Agency, Paris, France.

International Standards Organization (ISO), 2006. Greenhouse Gases 14064 - Part 2: Specification with Guidance at the Project Level for Quantification, Monitoring and Reporting of Greenhouse Gas Emission Reductions of Removal Enhancements. ISO, Geneva, Switzerland.

Jackson, T., 2009. Prosperity Without Growth? - The Transition to a Sustainable Economy. Sustainable Development Commission, UK.

Jasinski, J.P.P., Payette, S., 2005. The creation of alternative stable states in the southern boreal forest, Québec. Canada. Ecol. Monogr. 75, 561-583.

Juang, J.Y., Katul, G., Siqueira, M., Stou, P., Novick, K., 2007. Separating the effects of albedo from eco-physiological changes on surface temperature along a successional chronosequence in the southeastern United States. Geophys. Res. Lett. 34, L21408, http://dx.doi.org/10.1029/2007GL031296.

Kurtén, T., Kulmala, M., Dal Maso, M., Suni, T., Reissell, A., Vehkamäki, H., Hari, P., Laaksonen, A., Viisanen, Y., Vesala, T., 2003. Estimation of different forest-related contributions to the radiative balance using observations in southern Finland. Boreal Environ. Res. 8, 275-285.

Kurz, W.A., Dymond, C.C., White, T.M., Stinson, G., Shaw, C.H., Rampley, G.J., Smyth, C., Simpson, B.N., Neilson, E.T., Trofymow, J.A., Metsaranta, J., Apps, M.J., 2009. CBM-CFS3: a model of carbon-dynamics in forestry and land-use change implementing IPCC standards. Ecol. Model. 220, 480-504.

Kurz, W.A., Stinson, G., Rampley, G., 2007. Could increased boreal forest ecosystem productivity offset carbon losses from increased disturbances? Philos. Trans. R. Soc. B 2198, 1-9.

Kurz, W.A., Stinson, G., Rampley, G.J., Dymond, C.C., Neilson, E.T., 2008. Risk of natural disturbances makes future contribution of Canada's forests to the global carbon cycle highly uncertain. Proc. Natl. Acad. Sci. U.S.A. 105, 1551-1555.

Kirschbaum, M.U.F., 2006. Temporary carbon sequestration cannot prevent climate change. Mitig. Adapt. Strat. Global Change 11, 1151-1164.

Lee, X., 2010. Forests and climate: a warming paradox. Science 328, 1479.

Leu, S., 2010. Forests and climate: the search for specifics. Science 328, 1479-1480.

Madec, C., Walsh, D., Lord, D., Tremblay, P., Boucher, J.-F., Bouchard, S. Afforestation of black spruce lichen woodlands by natural seeding. North. J. Appl. Forest, in press.

Mallik, A.U., 1993. Ecology of a forest weed of Newfoundland: vegetative regeneration strategy of Kalmia angustifolia. Can. J. Botany 71, 161-166.

Mansuy, N., Gauthier, S., Bergeron, Y., 2012. Afforestation opportunities when stand productivity is driven by a high risk of natural disturbance: a review of the open lichen woodland in the eastern boreal forest of Canada. Mitig. Adapt. Strat. Global Change, http://dx.doi.org/10.1007/s11027-012-9362-x.

Marland, G., Fruit, K., Sedjo, R., 2001. Accounting for sequestered carbon: the question of permanence. Environ. Sci. Policy 4, 259-268.

Matthews, H.D., Caldeira, K., 2008. Stabilizing climate requires near-zero emissions. Geophys. Res. Lett. 35, L04705. 
Ministère du Développement Durable, de l'Environnement et des Parcs (MDDEP), 2011. Inventaire Québécois des émissions de gaz à effet de serre en 2009 et leur évolution depuis 1990. Gouvernement du Québec, Ministère du Développement Durable, de l'Environnement et des Parcs, Direction des politiques de la qualité de l'atmosphère, Québec, Canada.

Ministère des Ressources Naturelles (MRN), 2000. Mise à jour, Manuel d'aménagement forestier: Document d'annexes, Annexe 1, Les tables de rendement. Gouvernement du Québec, Ministère des Ressources Naturelles, Québec, Canada.

Ministère des Ressources Naturelles et de la Faune (MRNF), 2010. Ressources et industries forestière: Portrait statistique 2010. Gouvernement du Québec, Ministère des Ressources Naturelles et de la Faune, Québec, Canada.

Ministère des Ressources naturelles, de la Faune et des Parcs (MRNFP), 2003. Manuel d'Aménagement Forestier, 4ème éd. Gouvernement du Québec, Québec, Canada.

Montenegro, A., Eby, M., Mu, Q., Mulligan, M., Weaver, A.J., Wiebe, E.C., Zhao, M., 2009. The net carbon drawdown of small scale afforestation from satellite observations. Global Planet. Change 69, 195-204.

Nabuurs, G.J., Masera, O., Andrasko, K., Benitez-Ponce, P., Boer, R., Dutschke, M., Elsiddig, E., Ford-Robertson, J., Frumhoff, P., Karjalainen, T., Krankina, O., Kurz, W.A., Matsumoto, M., Oyhantcabal, W., Ravindranath, N.H., Sanz Sanchez, M.J., Zhang, X., 2007. Forestry. In: Metz, B., Davidson, O.R., Bosch, P.R., Dave, R., Meyer, L.A. (Eds.), Climate Change 2007: Mitigation. Contribution of Working Group III to the Fourth Assessment Report of the Intergovernmental Panel on Climate Change. Cambridge University Press, Cambridge, United Kingdom/New York, NY, pp. 541-584.

Obersteiner, M., Böttcher, H., Yamagata, Y., 2010. Terrestrial ecosystem management for climate change mitigation. Curr. Opin. Environ. Sust. 2, 271-276.

Organisation for Economic Co-operation and Development (OECD), 2012. OCED Environmental Outlook to 2050 - The Consequences of Inaction. OCED Publishing, Paris, France, http://dx.doi.org/10.1787/9789264122246-en.

Payette, S., 1992. Fire as a controlling process in the North American boreal forest. In: A Systems Analysis of the Global Boreal Forest. Cambridge University Press, Cambridge, UK, pp. 144-169.

Payette, S., Bhiry, N., Delwaide, A., Simard, M., 2000. Origin of the lichen woodland at its southern range limit in eastern Canada: the catastrophic impact of insect defoliators and fire on the spruce-moss forest. Can. J. Forest Res. 30, 288-305.

Perez-Garcia, J., Lipke, B., Comnick, J., Manriquez, C., 2005. An assessment of carbon pools, storage, and wood product market substitution using life cycle analysis results. Wood Fiber Sci. 37, 140-148.

Plante, F., 2003. Évaluation des superficies potentielles de remise en production des strates mal régénérées de la région 02.
Rapport de l'étape 3, Les Entreprises Gauthier, Parent, Ltée, pour le compte du Bureau régional 02 du MRNF, Québec, Canada.

Pothier, D., Savard, F., 1998. Actualisation des tables de production pour les principales espèces forestières $d u$ Québec. Gouvernement du Québec, Direction des inventaires forestiers, Québec, Canada.

Rowe, J.S., 1972. Forest Regions of Canada. Canadian Forestry Service Publication, Department of the Environment, Ottawa, Canada.

Shuman, J.K., Shugart, H.H., O'Halloran, T.L., 2011. Sensitivity of Siberian larch forests to climate change. Global Change Biol. 17, 2370-2384.

Shvidenko, A., Nilsson, S., Roshkov, V., 1997. Possibilities for increased carbon sequestration through the implementation of rational forest management in Russia. Water Air Soil Pollut. 94, 137-162.

Solomon, S., Plattner, G.-K., Knutti, R., Friedlingstein, P., 2009. Irreversible climate change due to carbon dioxide emissions. Proc. Natl. Acad. Sci. U.S.A. 106, 1704-1709.

The Copenhagen Diagnosis, Allison, I., Bindoff, N.L., Bindschadler, R.A., Cox, P.M., de Noblet, N., England, M.H., Francis, J.E., Gruber, N., Haywood, A.M., Karoly, D.J., Kaser, G., Le Quéré, C., Lenton, T.M., Mann, M.E., McNeil, B.I., Pitman, A.J., Rahmstorf, S., Rignot, E., Schellnhuber, H.J., Schneider, S.H., Sherwood, S.C., Somerville, R.C.J., Steffen, K., Steig, E.J., Visbeck, M., Weaver, A.J., 2009. Updating the World on the Latest Climate Science. The University of New South Wales Climate Change Research Centre (CCRC), Sydney, Australia.

Thiffault, N., Titus, B., Munson, A.D., 2005. Silvicultural options to promote seedling establishment on

Kalmia-Vaccinium-dominated sites. Scand. J. Forest Res. 20, 110-121.

Thiffault, N., Jobidon, R., 2006. How to shift unproductive Kalmia angustifolia - Rhododendron groenlandicum heath to productive conifer plantation. Can. J. Forest Res. 36, 2364-2376.

UNFCCC (CDM-Executive board), 2008. Tool for the Demonstration and Assessment of Additionality in A/R CDM Project Activities; version 02. EB 35 Report 02, Annex 17.

United Nations Population Fund (UNFPA), 2011. State of the World Population 2011. UNFPA, New York, USA.

Verified Carbon Standard (VCS), 2011. Agriculture, Forestry and Other Land Use (AFOLU) Requirements, VCS Version 3 Requirements Document, 19 October 2011, v3.1.

Weaver, A.J., Zickfeld, K., Montenegro, A., Eby, M., 2007. Long term climate implications of 2050 emission reduction targets. Geophys. Res. Lett. 34, L19703, http://dx.doi.org/10.1029/2007GL031018.

Yakir, D., Rotenberg, E., 2010. Response. Science 328, 1480.

Zickfeld, K., Eby, M., Matthews, H.D., Weaver, A.J., 2009. Setting cumulative emissions targets to reduce the risk of dangerous climate change. Proc. Natl. Acad. Sci. U.S.A. 106, 16129-16134. 